\title{
Anodic electrodissolution: A low cost alternative for carbon steel sample preparation for quantification of metals by ICP-MS
}

Bruno L. M. FERNANDES, * Taimara P. FERREIRA, * Rafael A. SOUSA*, Denise LOWINSOHN* ${ }^{\dagger}$ and Walter R. P. FILHO.**

* Department of Chemistry, Institute of Exact Science, Federal University of Juiz de Fora, Street José Lourenço Kelmer, 36036-900, Juiz de Fora/MG, Brazil.

** Department of Inorganic Chemistry, Jorge Duprat Figueiredo Foundation of occupational safety and medicine, Rua Capote Valente, 05409-002, São Paulo/SP, Brazil.

$\dagger$ To whom correspondence should be addressed.

E-mail: denise.lowinsohn@ufjf.edu.br 


\begin{abstract}
A fast and low-cost method using electrolysis for sample preparation of carbon steel present in weld electrodes aiming to quantification of heavy metals by Inductively Coupled Plasma Mass Spectrometry (ICP-MS) was developed. Conditions of the electrolysis, such as $\mathrm{pH}$ and electrical charge were investigated to higher the solubility and concentration for the analytes in the electrolyte. The method showed high reproducibility, with a relative standard deviation (RSD) of less than $3.05 \%$ and the recovery from $88.6 \%$ to $108.9 \%$ for the analytes demonstrate the accuracy of the developed method.
\end{abstract}




\section{Introduction}

Acid digestion is widely employed to dissolve steel samples before spectrometric quantification of metals. ${ }^{1-3}$ The acid digestion on a hot plate (ADHP) is a conventional and simple method of dissolution, ${ }^{4-9}$ which has several disadvantages, such as excessive consumption of reagents, pre-concentration of impurities, and the long digestion time. ${ }^{3,10}$ The use of electrolysis, named anodic electrodissolution (AE) to dissolve steel samples can be an alternative to minimize these problems.

The AE uses electrons for dissolving metallic samples, ${ }^{11}$ by applying direct current (DC) between the sample used as an anode and an inert cathode immersed in an electrolyte. $^{12}$ In this arrangement, the anode undergoes oxidation and the analytes migrate to the solution. ${ }^{2,13}$ Several examples that employing the AE for dissolving steels and other alloys are reported in the literature showing good results, which makes the use of this method feasible. ${ }^{14-19}$

This note describes a low-cost method of dissolution for carbon steel alloys presents in AWS A5.1 E6013 electrode employing AE into plastic syringes operated as container electrolytic and posterior quantification of $\mathrm{Co}, \mathrm{Cr}, \mathrm{Cu}, \mathrm{Ni}$, and $\mathrm{Pb}$ by ICP-MS. These samples are employed in the arc electric welding and the metals evaluated are normally added to the electrode for increases in strength, thermal conductivity, and hardening of the welded joint. ${ }^{20-23}$ 


\section{Experimental}

\section{Samples}

Samples of four different manufacturers (E1, E2, E3 and E4) carbon steels presents in AWS A5.1 E6013 welding electrodes were purchased from local ironmongery shops and stored in plastic bags to avoid contaminations.

\section{Reagents and chemicals}

$\mathrm{HNO}_{3}\left(65 \% \mathrm{ww}^{-1}\right.$, suprapur), $\mathrm{HCl}\left(37 \% \mathrm{ww}^{-1}\right.$, ultra pure), $\mathrm{KNO}_{3}(99 \%$ purity), $\mathrm{KCl}$ (99\% purity) were acquired from Sigma-Aldrich (Rio de Janeiro, Brazil). Standard metals solutions were prepared by dilution of $1000 \mathrm{mg} \mathrm{L}^{-1}$ standards acquired from SpecSol (São José dos Campos, Brazil). Disposable syringes (5.00 mL), acquired from local pharmacies, were used as electrolytic containers. Platinum rod $(5.00 \mathrm{~cm}, 1.6 \mathrm{~mm}$ diameter) acquired from Sigma-Aldrich (Rio de Janeiro, Brazil) was used as cathode. All glassware and syringes were pre-soaked in $10 \% \mathrm{vv}^{-1}$ of $\mathrm{HNO}_{3}$ in deionized water for at least $24 \mathrm{~h}$ and rinsed with deionized water prior to use.

All solutions were prepared using deionized water (Milli-Q-Quantum EX, with resistivity equal to $18.0 \mathrm{M} \Omega \mathrm{cm}$ ).

\section{Instrumentation}

An ICP-MS model 7700 (Agilent Technologies) was employed for the quantification of the present analytes in the steel samples. Instrumental parameters are shown in Table $\mathrm{S} 1$. 
Stabilized power supply (RadioNave R-3562) was employed to supply DC for AE. A hot plate model SP-140/D was purchased from SP labor (Presidente Prudente, Brazil) and used for ADHP.

\section{Preparation of samples by $A E$}

AE was conducted in disposable plastic syringes of $5.00 \mathrm{~mL}$ (Fig. 1). The steel samples were accommodated at the top of the syringe while the cathode of platinum was docked at the other end, closing a circuit on the electrodes after adding the electrolyte. The amount of electrodissolved mass (EM) was determined by the weighing of the steel samples before and after the electrodissolution process.

The $\mathrm{pH}$ effect was investigated to increase $\mathrm{AE}$ efficiency. For that, approximately $1 \mathrm{~cm}$ of the sample E1 was cut and polished with commercial 80/100 mesh granulation sandpaper for removing oxides. Solutions of $\mathrm{HNO}_{3} 1.0(\mathrm{pH}=0), 0.01$ $(\mathrm{pH}=2)$ and $0.0001 \mathrm{~mol} \mathrm{~L}^{-1}(\mathrm{pH}=4)$ were used. The effect in $\mathrm{pH}$ equal to 7 was rated using solution $1.0 \mathrm{~mol} \mathrm{~L}^{-1}$ of $\mathrm{KNO}_{3}$. An electrical charge equal to $240 \mathrm{C}$ was used. In summary, the effect that the presence of chloride ions causes in the amount of EM employing the $\mathrm{AE}$ was rated using an electrolyte containing $\mathrm{HCl} 0.1 \mathrm{~mol} \mathrm{~L}-1$ and $\mathrm{HNO}_{3}$ $1.0 \mathrm{~mol} \mathrm{~L}{ }^{-1}$.

A study of the effect of the electrical charge in increase to EM was investigated by the application of $240,300,600,900,1200$, and $1500 \mathrm{C}$ between the samples and the cathode in the syringe.

Preparation of samples by ADHP

The ADHP was performed using open flasks. In about $0.1 \mathrm{~g}$ of the carbon steel samples were added $3 \mathrm{~mL}$ of concentrated $\mathrm{HNO}_{3}$ and $1 \mathrm{~mL}$ of concentrated $\mathrm{HCl}$ at a 
temperature of $80{ }^{\circ} \mathrm{C}$ under reflux. The mixture of $\mathrm{HNO}_{3}: \mathrm{HCl}(3: 1)$ is used for the rapid dissolution of metal alloys since it favors the formation of strongly oxidizing and complexing products. ${ }^{24,25}$

\section{Analysis by ICP-MS}

The dissolved samples from AE and ADHP preparations were transferred to 10and 25-mL volumetric flasks, respectively, and diluted with deionized water. For analysis by ICP-MS, the samples were diluted an additional 20 times with deionized water to ensure that the concentration of the analytes in the samples adjust to the external calibration curve.

For the quantification of the metals by ICP-MS, external calibration curves were constructed by diluting the metal standards $1000 \mathrm{mg} \mathrm{L}^{-1}$ in $\mathrm{HNO}_{3}$ medium $\left(2 \% \mathrm{vv}^{-1}\right)$. The concentration of the standards ranged from 0.1 to $100.0 \mu \mathrm{g} \mathrm{L}^{-1}$ and the linear regressions were provided by the software itself.

For the recovery study, a final concentration de $1.8 \mathrm{mg} \mathrm{L}^{-1}$ of the standards of Co, $\mathrm{Cr}, \mathrm{Cu}, \mathrm{Ni}$, and $\mathrm{Pb}$ was adding to one of the samples before dissolutions using $\mathrm{AE}$ and ADHP

\section{Results and Discussion}

\section{Optimization of AE conditions:}

As presented in Fig. 2 amount of EM decreases with the increase of $\mathrm{pH}$, making the $\mathrm{HNO}_{3} 1.0 \mathrm{~mol} \mathrm{~L}$-1 the electrolyte more efficient. This acid is also known to form soluble metallic nitrates. ${ }^{26}$

The presence of $\mathrm{HCl}$ in the electrolyte resulted in an increase of $21.6 \%$ in the 
amount of EM. The addition of chloride ions favors the solubility of the analytes, once these ions are good complexing agents. ${ }^{25}$ The combination of $\mathrm{HNO}_{3}\left(1.0 \mathrm{~mol} \mathrm{~L}^{-1}\right)$ with $\mathrm{HCl}\left(0.1 \mathrm{~mol} \mathrm{~L}^{-1}\right)$ was chosen like electrolyte for dissolution of the samples by AE.

A linear relationship between the amount of EM and the electric charge supplied to $\mathrm{AE}$ was observed, evidencing that the process is governed by Faraday laws of electrolysis (Fig. 3). ${ }^{27,28}$ This relationship makes it possible to control the dissolved mass through monitoring the supplied electric charge.

An electric charge of $900 \mathrm{C}$ (3A for $300 \mathrm{~s}$ ) was employed in the dissolution by AE because it provided a good trade-off between efficiency and accuracy required. In the ADHP the dissolution time was from 30 minutes.

The dissolution by AE resulted in adequate repeatability, obtaining RSD equal to $3.05 \%$ for 10 measurements of electrodissolution. The samples E1, E2, E3, and E4 were electrodissolved in triplicate and the EM ranged from 30.3 to $35.1 \mathrm{mg}$.

Sample analysis by ICP-MS.

The limits of quantification (LOQ) for each analyte were determined based on the IUPAC definition ${ }^{29}$ and were equal to $0.034 \mu \mathrm{g} \mathrm{L}^{-1}$ for $\mathrm{Co}, 0.070 \mu \mathrm{g} \mathrm{L}^{-1}$ for $\mathrm{Cr}, 0.086$ $\mu \mathrm{g} \mathrm{L}{ }^{-1}$ for $\mathrm{Cu}, 0.065 \mu \mathrm{g} \mathrm{L}^{-1}$ for $\mathrm{Ni}$ and $0.070 \mu \mathrm{g} \mathrm{L^{-1 }}$ for $\mathrm{Pb}$.

The results of the quantification of $\mathrm{Co}, \mathrm{Cr}, \mathrm{Cu}, \mathrm{Ni}$, and $\mathrm{Pb}$ by ICP-MS employing the AE and ADHP are presented in Table S2. The accuracy study of the AE showed values $>88 \%$ evidencing that the method has adequate accuracy. The t-test (95\% confidence) was used to compare the results obtained by the two methods of dissolution, where was observed that the averages obtained by $\mathrm{AE}$ are equal to those obtained by ADHP (conventional method). 


\section{Conclusions}

A low-cost method for dissolution of carbon steel samples presents in the weld electrode AWS A5.1 E6013 using electrodissolution was proposed. The process was carried out on disposable syringes, using diluted acids and in a dissolution time of only 300 s. Recovery values above $88 \%$ were obtained for all analytes indicating proper accuracy, making the method $\mathrm{AE}$ a viable alternative to the dissolution of steel alloy.

\section{Acknowledgements}

We are grateful for the financial support of the CAPES (Coordenação de Aperfeiçoamento de Pessoal de Nível Superior), CNPQ (Conselho Nacional de Desenvolvimento Científico e Tecnológico) and FAPEMIG (Fundação de Amparo à Pesquisa do Estado de Minas Gerais).

\section{Supporting Information}

Tables S1 and S2 is available free of charge on the Web at http://www.jsac.or.jp/analsci/. 


\section{References}

1. T. Grigoletto, E. De Oliveira, and I. G. R. Gutz, Talanta, 2005, 67, 791.

2. E. V. Yakubenko, Z. A. Voitkova, I. I. Chernikova, and T. N. Ermolaeva, Inorg. Mater., 2015, 51, 1370.

3. J. B. B. Da Silva, I. G. De Souza, and A. P. G. Gervasio, Quim. Nova, 2000, 23, 244.

4. V. Zare-Shahabadi, P. Asaadi, F. Abbasitabar, and A. Shirmardi, J. Braz. Chem. Soc., $2017,28,887$.

5. H. Jingyu, L. Zheng, and W. Haizhou, Anal. Chim. Acta, 2002, 451, 329.

6. T. P. Ferreira, R. A. De Sousa, and D. Lowinsohn, Anal. Methods, 2016, 8, 8028.

7. V. Berisha, A. Veliu, and M. Shala, J. Int. Environ. Appl. Sci., 2018, 13, 174.

8. T. SUMITA and Y. KOBAYASHI, J. Japanese Soc. Exp. Mech., 2019, 18, 247.

9. N. R. Bader, Rasayan J. Chem., 2011, 4, 49.

10. E. De Oliveira, J. Braz. Chem. Soc., 2003, 14, 174.

11. K. Jüttner, U. Galla, and H. Schmieder, Electrochim. Acta, 2000, 45, 2575.

12. K. Charleton, T. Buffie, and D. M. Goltz, Talanta, 2007, 74, 7.

13. J. B. Borba Da Silva, M. B. Oss Giacomelli, I. Gonçalves de Souza, and A. J. Curtius, Talanta, 1998, 47, 1191.

14. C. L. LUKE, Anal. Chem., 1958, 30, 1405.

15. K. . OHLS and K. H. KOCH, Fresenius' Z. Anal. Chem., 1987, 326, 520.

16. H. Bergamin F, F. J. Krug, E. A. G. Zagatto, E. C. Arruda, and C. A. Coutinho, Anal. Chim. Acta, 1986, 190, 177.

17. H. Bergamin F, F. J. Krug, B. F. Reis, J. A. Nobrega, M. Mesquita, and I. G. Souza, Anal. Chim. Acta, 1988, 214, 397. 
18. J. Flock and K. Ohls, Fresenius' Zeitschrift für Anal. Chemie, 1988, 331, 408.

19. I. G. Souza, H. Bergamin Fo, F. J. Krug, J. A. Nóbrega, P. V. Oliveira, B. F. Reis, and M. F. Giné, Anal. Chim. Acta, 1991, 245, 211.

20. D. Purnama, W. Winarto, N. Sofyan, A. Prihastomo, and K. Ito, Int. J. Technol., 2020 .

21. A. J. C. Gomes, J. C. F. Jorge, I. S. Bott, L. F. G. Souza, M. C. Mendes, and L. S. Araújo, Metallogr. Microstruct. Anal., 2019, 8, 815.

22. H. R. Silva and V. A. Ferraresi, Wear, 2019, 426-427, 302.

23. M. H. Avazkonandeh-Gharavol, M. Haddad-Sabzevar, and A. Haerian, Mater. Des., 2009, 30, 1902.

24. F. J. Krug, "Workshop sobre preparo de amostras", 2006.

25. F. L. F. Silva, T. A. O. Duarte, L. S. Melo, L. P. D. Ribeiro, S. T. Gouveia, G. S. Lopes, and W. O. Matos, Talanta, 2016, 146, 188.

26. A. P. G. Gervasio, G. C. Luca, A. A. Menegário, B. F. Reis, and H. B. Filho, Anal. Chim. Acta, 2000, 405, 213.

27. N. Thi Bich Nhung, D. Thanh Liem, and T. Quoc Thanh, Sci. Technol. Dev. J. Eng. Technol., 2020, 3, First.

28. M. Aimoto, H. Kondo, and A. Ono, Anal. Sci., 2007, 23, 1367.

29. INMETRO, Instituto Nacional de Metrologia e Normalização e Qualidade Industrial. 


\section{Figure Captions}

Fig. 1 Disposable plastic syringes of $5.00 \mathrm{~mL}$ used as electrolytic container.

Fig. 2 Relationship between the amount of EM and the $\mathrm{pH}$ of the electrolyte in the AE process.

Fig. 3 Relationship between electrical charge supplied for AE and amount of the EM

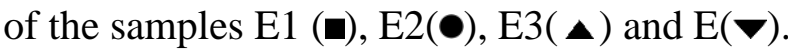




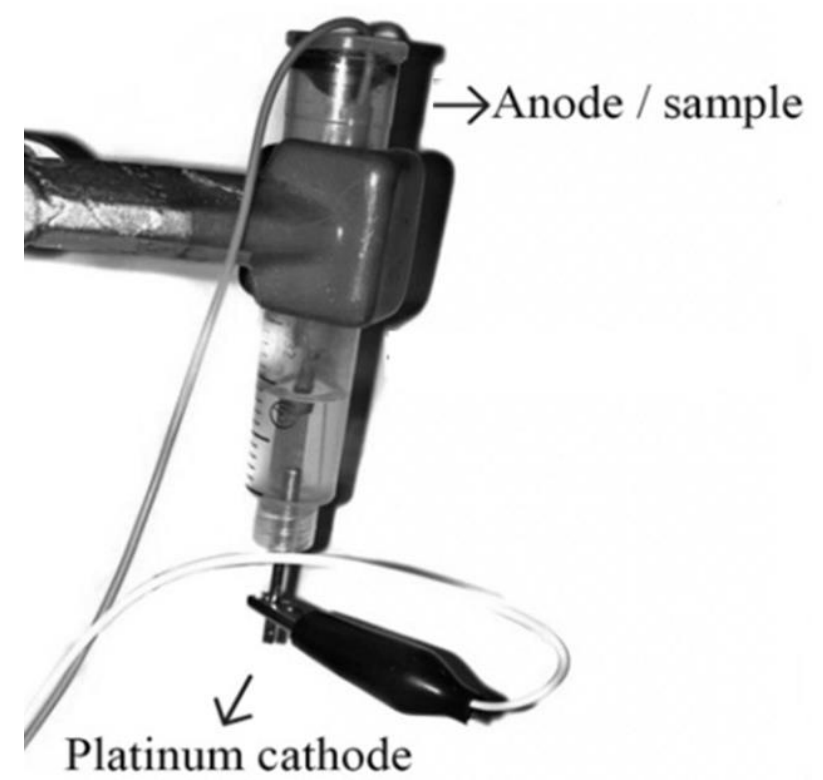

Fig. 1

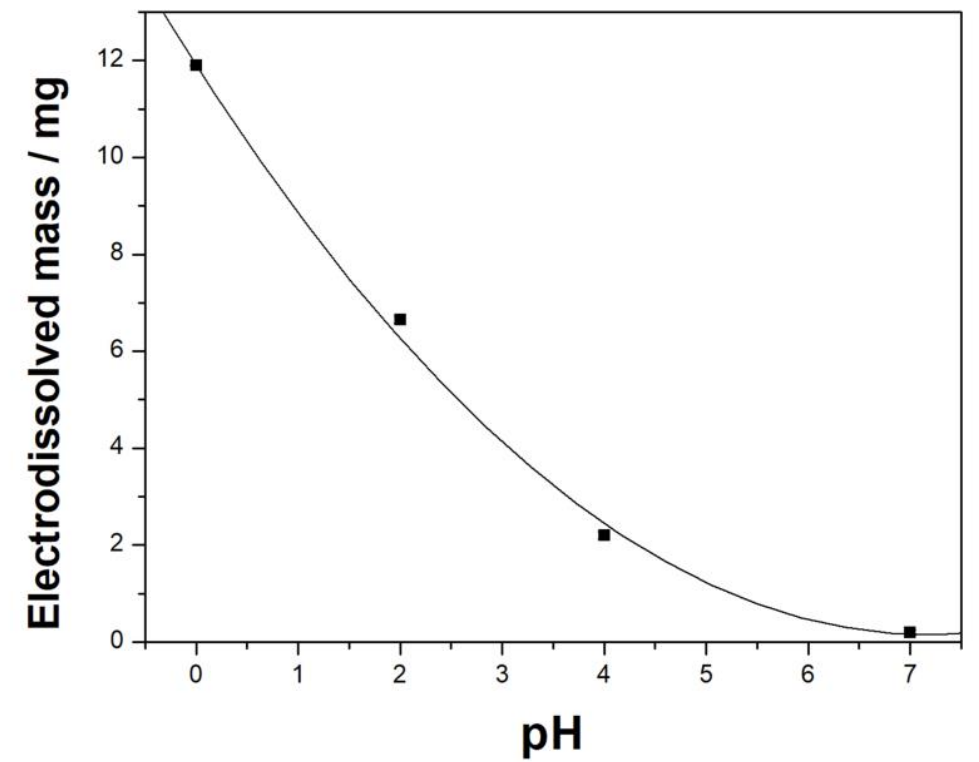

Fig. 2 


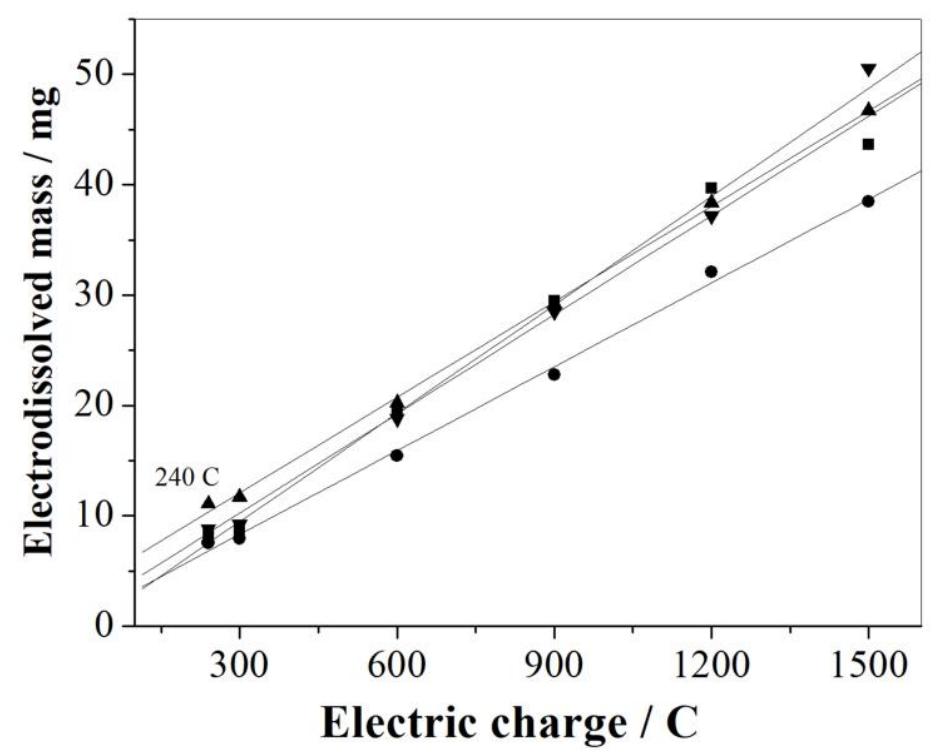

Fig. 3 


\section{Graphical Index}

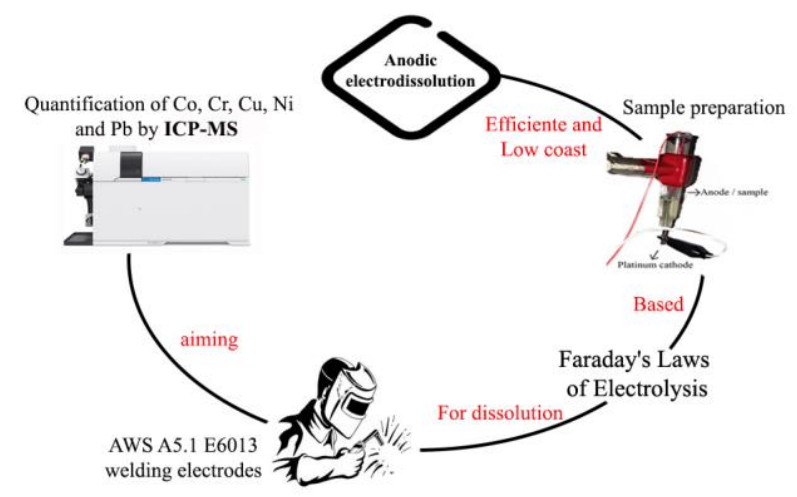

